Supporting Information for

\title{
Selective Co-oligomerization of Ethylene and 1-Hexene by Chromium-PNP Catalysts: A DFT Study
}

Minglan Gong, Zhen Liu, * Yuanhui Li, Yue Ma, Qiaoqiao Sun, Jialong Zhang and Boping Liu*

State Key Laboratory of Chemical Engineering, East China University of Science and Technology, Meilong Road 130, Shanghai 200237, People's Republic of China liuzhen@ecust.edu.cn, boping@ecust.edu.cn 


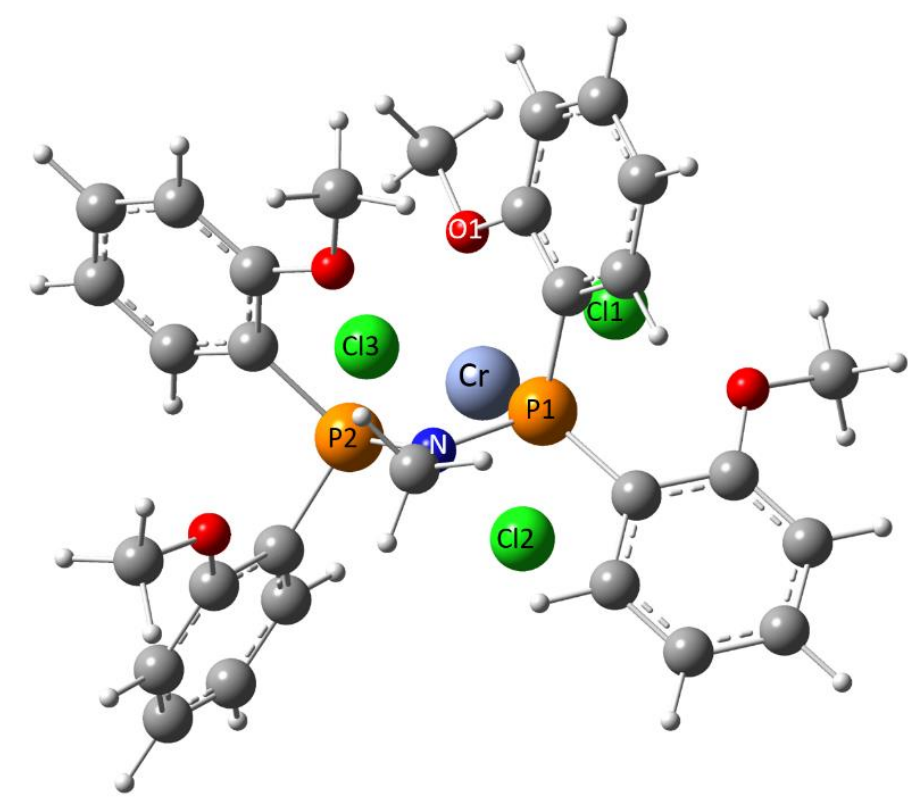

Figure S1. Optimized geometry of $\left[\mathrm{CrCl}_{3}\left(\mathrm{PNP}^{\mathrm{OMe}}\right)\right] \quad\left(\mathrm{PNP}^{\mathrm{OMe}}\right.$ $\left.\left.=o-\mathrm{MeOC}_{6} \mathrm{H}_{4}\right)_{2} \mathrm{PN}\left(\mathrm{CH}_{3}\right) \mathrm{P}-\left(o-\mathrm{MeOC}_{6} \mathrm{H}_{4}\right)_{2}\right)$. Selected bond distances $(\AA)$ and angles $\left(^{\circ}\right)$ : Cr-O 2.432, Cr-P1 2.476, Cr-P2 2.598, Cr-C11 2.288, Cr-C12 2.271, Cr-Cl3 2.306; O1-Cr-C12 161.47, O1-Cr-C11 83.50, O1-Cr-Cl3 96.43, C12-Cr-Cl1 97.92, C2-Cr-C13 101.46, C11-Cr-Cl3 100.16, O1-Cr-P1 71.47, O1-Cr-P2 81.25, P1-Cr-P2 65.45. 
Table S1. Comparison of experimental and computational bond distances $\left(\mathrm{A}^{\circ}\right)$ and angles $\left(^{\circ}\right)$ for $\left.\left[\mathrm{CrCl}_{3}\left(\mathrm{PNP}^{\mathrm{OMe}}\right)\right]\left(\mathrm{PNP}^{\mathrm{OMe}}=o-\mathrm{MeOC}_{6} \mathrm{H}_{4}\right)_{2} \mathrm{PN}\left(\mathrm{CH}_{3}\right) \mathrm{P}\left(o-\mathrm{MeOC}_{6} \mathrm{H}_{4}\right)_{2}\right)$.

\begin{tabular}{|c|c|c|}
\hline & Experiment $^{1}$ & DFT \\
\hline $\mathrm{Cr}-\mathrm{O} 1$ & $2.1562(15)$ & 2.432 \\
\hline $\mathrm{Cr}-\mathrm{P} 1$ & $2.3855(7)$ & 2.476 \\
\hline $\mathrm{Cr}-\mathrm{P} 2$ & $2.5098(7)$ & 2.598 \\
\hline $\mathrm{Cr}-\mathrm{Cl} 2$ & $2.2776(6)$ & 2.271 \\
\hline $\mathrm{Cr}-\mathrm{Cl}$ & $2.2937(6)$ & 2.288 \\
\hline $\mathrm{Cr}-\mathrm{Cl}$ & $2.3210(7)$ & 2.306 \\
\hline $\mathrm{O} 1-\mathrm{Cr}-\mathrm{Cl} 2$ & $165.62(4)$ & 161.47 \\
\hline $\mathrm{O} 1-\mathrm{Cr}-\mathrm{Cl}$ & $85.10(4)$ & 83.50 \\
\hline $\mathrm{O} 1-\mathrm{Cr}-\mathrm{Cl} 3$ & $97.71(4)$ & 96.43 \\
\hline $\mathrm{Cl} 2-\mathrm{Cr}-\mathrm{Cl}$ & $95.06(2)$ & 97.92 \\
\hline $\mathrm{Cl} 2-\mathrm{Cr}-\mathrm{Cl} 3$ & $96.48(2)$ & 101.46 \\
\hline $\mathrm{Cl1}-\mathrm{Cr}-\mathrm{Cl} 3$ & $98.79(2)$ & 100.16 \\
\hline $\mathrm{O} 1-\mathrm{Cr}-\mathrm{P} 1$ & $75.92(4)$ & 71.47 \\
\hline $\mathrm{Cl} 2-\mathrm{Cr}-\mathrm{P} 1$ & $89.82(2)$ & 90.15 \\
\hline $\mathrm{C} 11-\mathrm{Cr}-\mathrm{P} 1$ & $97.39(2)$ & 100.17 \\
\hline $\mathrm{Cl}-\mathrm{Cr}-\mathrm{P} 1$ & $162.03(2)$ & 154.90 \\
\hline $\mathrm{O} 1-\mathrm{Cr}-\mathrm{P} 2$ & $84.11(4)$ & 81.25 \\
\hline $\mathrm{Cl} 2-\mathrm{Cr}-\mathrm{P} 2$ & $92.01(2)$ & 93.44 \\
\hline $\mathrm{C} 11-\mathrm{Cr}-\mathrm{P} 2$ & $162.47(2)$ & 161.77 \\
\hline $\mathrm{Cl} 3-\mathrm{Cr}-\mathrm{P} 2$ & $96.31(2)$ & 91.45 \\
\hline $\mathrm{P} 1-\mathrm{Cr}-\mathrm{P} 2$ & $66.56(2)$ & 65.45 \\
\hline
\end{tabular}


Table S2. Free energies (Ha) of 2, 3, 7, 8 and $\mathbf{9}$ under different spin states from B3LYP and M06L and the gap $(\triangle E)$ in the two energy barriers for the former minus the latter.

\begin{tabular}{|c|c|c|c|c|c|c|}
\hline & \multicolumn{2}{|c|}{ B3LYP } & \multicolumn{2}{|c|}{ M06L } & \multicolumn{2}{|c|}{$\triangle \mathrm{E}$} \\
\hline & quartet & sextet & quartet & sextet & quartet & sextet \\
\hline 2 & 2327.04459 & 2327.03854 & 2326.63349 & 2326.61827 & -0.41110 & -0.42027 \\
\hline 3 & 2405.63124 & 2405.63007 & 2405.19319 & 2405.18460 & -0.43805 & -0.44547 \\
\hline 7 & 2484.25876 & 2484.25614 & 2483.80123 & 2483.79253 & -0.45753 & -0.46361 \\
\hline 8 & 2484.26452 & 2484.25902 & 2483.80506 & 2483.79225 & -0.45946 & -0.46677 \\
\hline 9 & 2562.85109 & 2562.85215 & 2562.36776 & 2562.36118 & -0.48333 & -0.49097 \\
\hline
\end{tabular}

To check the occurrence of spin surface crossing, single point energy calculations of $2,3,7,8$ and 9 were carried out using local density functional M06L with the same triple- $\zeta$ basis set $(\operatorname{lan} 12 \mathrm{tz}$ for $\mathrm{Cr}, 6-311 \mathrm{G}(\mathrm{d}, \mathrm{p})$ for other elements). Free energies in Table S2 were the combination with geometry optimizations energy and single point energy. The M06L functional possessing good accuracy in reaction energy barrier is not likely to overestimate the stability of high-spin forms and also has been used to address the spin-state change problems. ${ }^{2}$ Free energies of $2,3,7,8$ and 9 under different spin states were exhibited in Table S2. Both functionals show a similar trend in predicting the ground state. Thus, occurrence of spin surface crossing is confirmed and the results from B3LYP calculation can be reliable. 


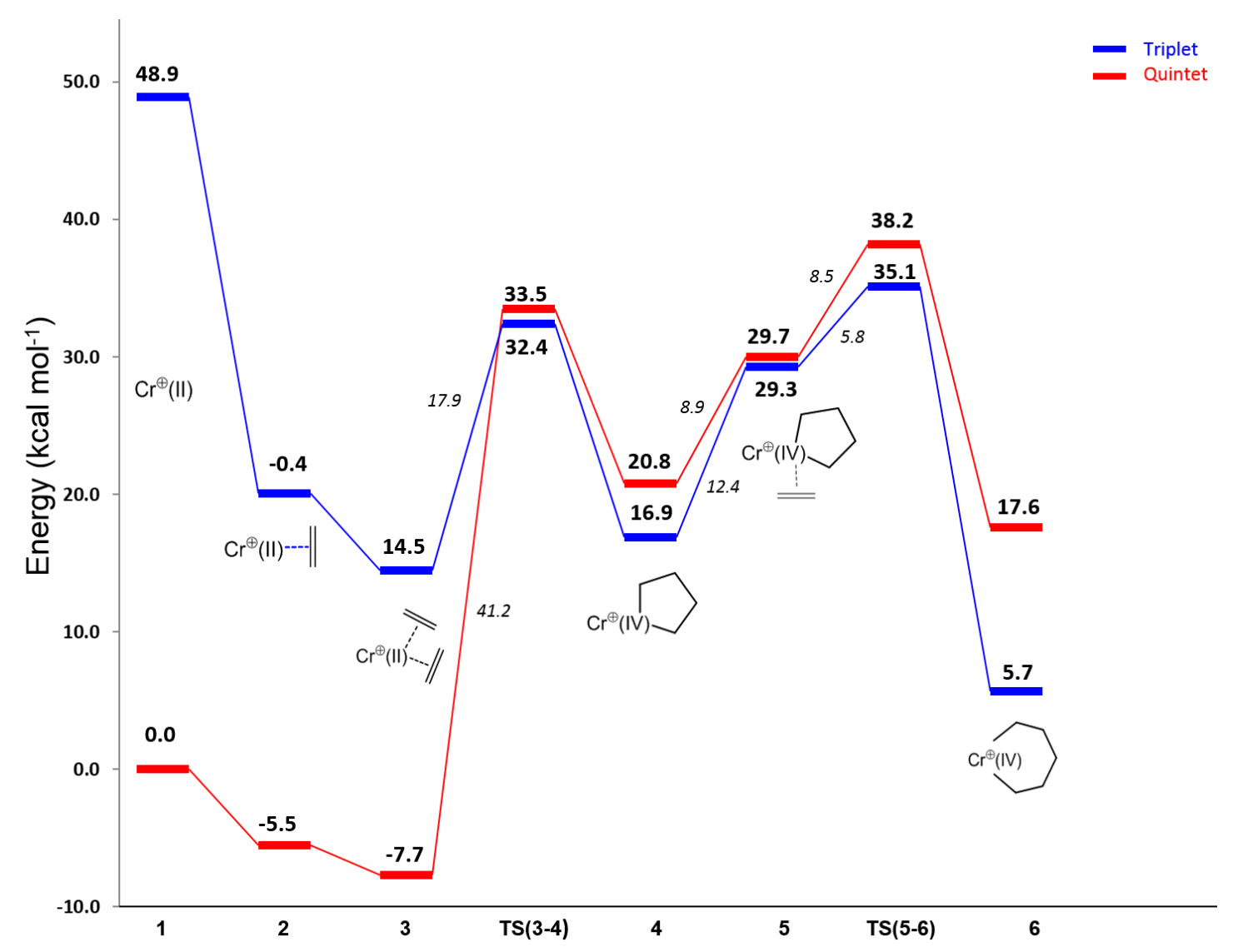

Figure S2. Calculated free energy diagram for ethylene trimerization via $\mathrm{Cr}(\mathrm{II}) / \mathrm{Cr}(\mathrm{IV})$ redox cycle $\left(\mathrm{kcal} / \mathrm{mol}\right.$, relative to ${ }^{5} \mathbf{1}$ plus the corresponding number of free ethylene molecules). Blue lines and red lines illustrate free energy surfaces in the triplet and quintet states, respectively. Energy barriers are indicated in italics.

As shown in Figure S2, it is found that the chromium center coordinating with two ethylene in the quintet state is associated with a Gibbs free energy barrier of around $40 \mathrm{kcal} / \mathrm{mol}$, much higher than energy at $\mathrm{Cr}(\mathrm{I}) / \mathrm{Cr}(\mathrm{III})$ cycle. Throughout the whole $\mathrm{Cr}(\mathrm{II}) / \mathrm{Cr}(\mathrm{IV})$ reaction pathway, potential energy surface is generally high which reveals $\mathrm{Cr}(\mathrm{II}) / \mathrm{Cr}(\mathrm{IV})$ redox cycle for ethylene trimerization is less preferred theoretically in this system. 


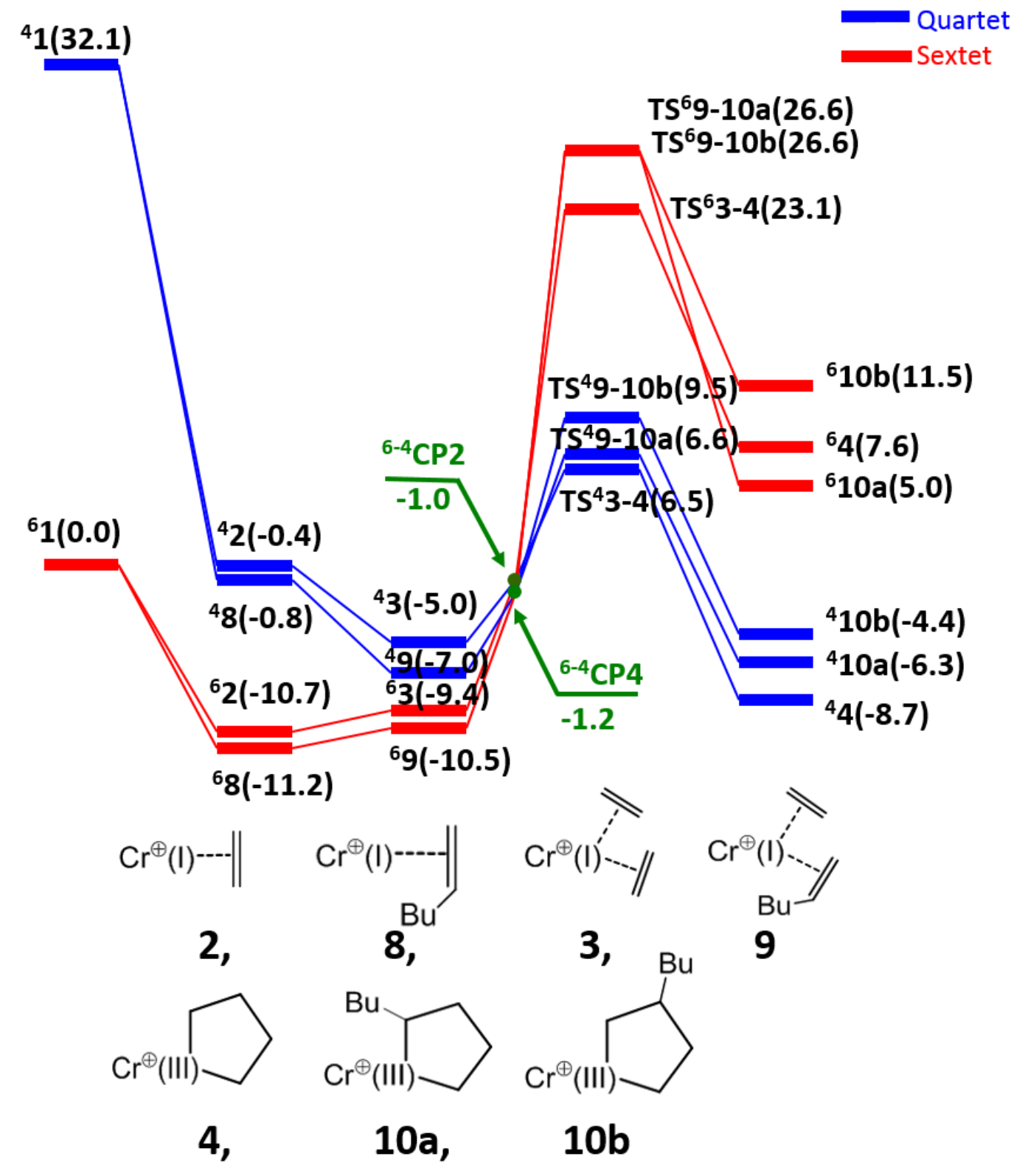

Figure S3. Calculated free energy diagram for ethylene co-oligomerization of chromacyclopentane formation $\left(\mathrm{kcal} / \mathrm{mol}\right.$, relative to ${ }^{\mathbf{6}} \mathbf{1}$ plus the corresponding number of free ethylene and 1-hexene molecules). Every intermediates and transition states are both shown in the quartet and sextet states. Blue lines and red lines illustrate free energy surfaces in the quartet and sextet states, respectively. Green points represent MECPs, and the free energies of them are shown in green together. For clarity reasons the ligand of $\left(\mathrm{PNP}^{\mathrm{OMe}}\right)$ has been omitted. 


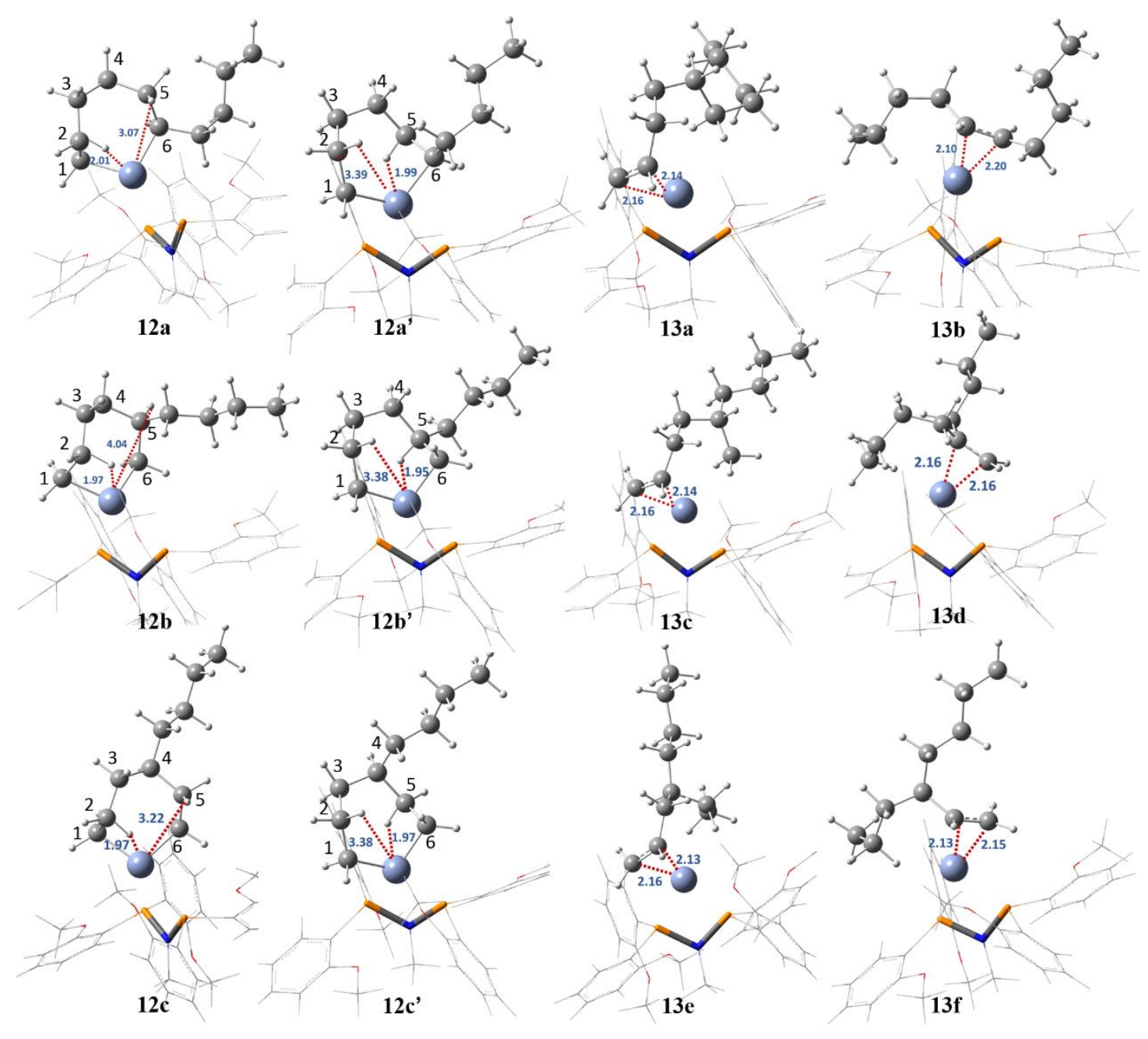

Figure S4. Metallocyclic structures and olefin coordination structures for $\beta$-hydrogen transfer pathways for ethylene co-oligomerization. Bond distances are in angstroms.

Figure S4 shows the whole chromacycloheptane (clockwise structures and counterclockwise structures) including 12a-c, $12 \mathbf{a}^{\prime}-\mathbf{c}^{\prime}$ and their corresponding structures after $\beta$-hydrogen transfer such as 13a-f in ethylene co-oligomerization. In 12a-c structures, the $\beta$-hydrogen agostic interaction is contributed by the hydrogen atom from $\mathrm{C} 2$, while the $\beta$-hydrogen agostic interaction is contributed by the hydrogen atom from C5 in $\mathbf{1 2} \mathbf{a}^{\prime}-\mathbf{c}^{\prime}$ structures. 
The supplemental file molecule contains the computed Cartesian coordinates of all of the molecules reported in this study. The file may be opened as a text file to read the coordinates, or opened directly by a molecular modeling program such as Mercury (version 3.3 or later, http://www.ccdc.cam.ac.uk/pages/Home.aspx) for visualization and analysis. It is a text file of all computed molecule Cartesian coordinates in .xyz format for convenient visualization. 


\section{Reference}

(1) Agapie, T.; Schofer, S. J.; Labinger, J. A.; Bercaw, J. E. J. Am. Chem. Soc. 2004, 126, 1304-1305.

(2) McGuinness, D. S.; Chan, B.; Britovsek, G. J. P.; Yates, B. F. Aust. J. Chem. 2014, 67, 1481-1490. 